\title{
Variation in Aggressiveness of Ash Yellows Phytoplasmas
}

\author{
W. A. Sinclair and H. M. Griffiths, Department of Plant Pathology, Cornell University, Ithaca, NY 14853-4203
}

\begin{abstract}
Sinclair, W. A., and Griffiths, H. M. 2000. Variation in aggressiveness of ash yellows phytoplasmas. Plant Dis. 84:282-288.

Twelve strains of phytoplasmas belonging to the ash yellows (AshY) group, from across the known range of AshY and representing six host species, were assessed for differences in ability to suppress growth and cause chlorosis in graft-inoculated Fraxinus pennsylvanica (green ash) and Catharanthus roseus (periwinkle). In each of two experiments with ash and one with periwinkle, different strains caused significantly different degrees of growth suppression and loss of foliar greenness. These growth and color impacts were positively and significantly correlated among experiments and between ash and periwinkle, indicating strain variation in aggressiveness. After two strains that differed in aggressiveness were coinoculated to periwinkle plants, polymerase chain reaction/restriction fragment length polymorphism (PCR/RFLP) assays of DNA from leaves remote from the inoculation sites revealed the presence of the aggressive strain sooner and more frequently than that of the less aggressive strain. Thus, aggressiveness was associated with more rapid multiplication and/or movement than was achieved by the less aggressive strain. When either strain was inoculated 11 weeks before the other into the same plant, only the initial strain could be detected after a further 12 weeks of incubation. Thus, the initial strain or its effect on the host may have interfered with multiplication and/or long-distance movement of the second strain. A concept of preemptive dominance is proposed to account for detection by primary PCR of only single phytoplasma strains in plants that may harbor two or more strains.
\end{abstract}

Additional keywords: cross-protection, virulence

Ash yellows (AshY), a cause of slow growth and decline in Fraxinus (ash) $(31,32)$, is caused by phytoplasmas belonging to a genetically discrete group $(19,20,29)$ designated 'Candidatus Phytoplasma fraxini' (12). Strains of this group, herein called the AshY group, have been found only in Fraxinus and the closely related genus Syringa (lilac) in North America and are unknown on other continents, except for a possible member in Prunus in China (21). Strains of AshY phytoplasmas from naturally infected ash or lilac have been separated into four subgroups based on sequence variations in ribosomal and nonribosomal DNA (12). The term strain, as used herein, refers to phytoplasma populations obtained from single naturally infected plants and maintained in ash or Catharanthus roseus (periwinkle). Phenotypic variation in AshY phytoplasmas has not been reported.

In our preliminary work, certain strains of AshY phytoplasmas inoculated to periwinkle caused yellowing and growth decline sooner than others did. Strain variation in aggressiveness sensu Van der Plank

Corresponding author: W. A. Sinclair

E-mail: was1@cornell.edu

Accepted for publication 30 November 1999.

Publication no. D-2000-0118-05R

(c) 2000 The American Phytopathological Society
(40) might explain the observed differences. This possibility was tested in a set of five experiments. Objectives were to determine whether strains of AshY phytoplasmas vary in aggressiveness in ash or in periwinkle, whether levels of aggressiveness across an array of strains in ash are correlated with levels in periwinkle, and whether different degrees of aggressiveness of selected strains could be due to differences in multiplication rates. Portions of this work were reported in an abstract (11).

\section{MATERIALS AND METHODS}

Plant materials and experimental conditions. Plants of periwinkle cultivar Little Pinkie were initially grown from seed and were propagated by cuttings thereafter. Green ash (Fraxinus pennsylvanica) seedlings were obtained as dormant 1-year-old stock from a nursery. Velvet ash ( $F$. velutina) plants, which served as inoculum sources, were raised from seed in a greenhouse. All plants were grown in a fertilized mixture of equal volumes soil, sand, and peat moss. Hereinafter we designate ages of, and the duration of experiments with, ash trees in terms of growth periods, because the duration and timing of growth and dormancy cycles of experimental plants did not coincide with natural growing seasons. Ash trees were grown in pots of 3-liter capacity during their first and second growth periods, and in pots of 19-liter capacity thereafter.
Rooted periwinkle cuttings were grown in 3 -liter pots after 7 months of growth in smaller containers. During growth, plants were fertilized weekly with dilute watersoluble fertilizer (15-5-15 N-P-K with micronutrients). Growth periods of ash trees lasted 4 or 5 months. After growth periods, ash stems were severed $30 \mathrm{~cm}$ above the soil, and the tops were discarded. Stumps were stored in their pots at 2 to $4^{\circ} \mathrm{C}$ in darkness for 4 months or longer for dormancy and vernalization before new sprouts were allowed to grow.

Experiments were performed in a screened greenhouse with natural light augmented by high-intensity-discharge sodium lamps to provide $16-\mathrm{h}$ photoperiod. Temperature ranges were 17 to $30^{\circ} \mathrm{C}$ during autumn-spring and 17 to $35^{\circ} \mathrm{C}$ during spring-summer. Plants in experiments were randomized, and ash were pruned early in each growth period to retain one dominant stem per plant.

Plants that served as sources of inoculum and those in phytoplasma treatments were inoculated by grafting. Periwinkle scions were leafy shoot tips 6 to $8 \mathrm{~cm}$ long. Ash scions were either rectangular bark patches (approximately $4 \times 25 \mathrm{~mm}$ ) or shoot segments 8 to $10 \mathrm{~cm}$ long. Each segment had at least one leaf-bearing node and a woody base. Shoot tips or segments serving as scions were cleft-grafted. Bark patches were grafted into fresh wounds, the same size and shape as the patch, on mainstems. Graft unions were wrapped with paraffin film (on periwinkle) or grafting rubbers (on ash). Cleft grafts were enclosed in polyethylene bags for 3 to 4 weeks, until vascular connections could sustain transpiration. Phytoplasmal infection of velvet ash trees used as inoculum sources was verified by the DAPI $\left(4^{\prime}, 6-\right.$ diamidino-2-phenylindole-2HCl) fluorescence test $(28,36)$. Infection of inoculated plants and controls was assayed by the same test one full growth cycle after inoculation. Inoculated plants that escaped infection, based on this assay, were deleted from experiments.

Phytoplasma strains. Samples of phytoplasma-infected Fraxinus or Syringa representing three species of each genus were obtained from 12 naturally infected source plants in nine localities (Table 1). Most samples consisted of twigs with foliage; one sample was a root segment, and one was a potted lilac. Phytoplasmal infection was initially detected or verified by means of the DAPI test. Phytoplasmas were transmitted by grafting to potted velvet ash and were maintained in this spe- 
cies. Phytoplasma strains were further transmitted by Cuscuta subinclusa (dodder) to periwinkle and then were maintained in this species by serial grafting. All strains were identified as members of the AshY group by restriction fragment length polymorphism (RFLP) and/or sequence analyses of rDNA (12).

Measurements and analyses. For ash trees, stem diameter $10 \mathrm{~cm}$ above the root collar was measured after the second and subsequent growth periods, and shoot length was measured after the final period. Final height and diameter data were integrated into a volume index, (stem diameter in millimeters $)^{2} \times$ height in centimeters $\times$ $10^{-3}$, for analysis (37). Foliar color was measured in two experiments, using a Minolta Chlorophyll Meter Model SPAD-502 (Spectrum Technologies Inc., Plainfield, IL). Metered values from this hand-held instrument are obtained by passing a light beam through a leaf that is briefly clamped between the beam source and sensor. The instrument gives values that are positively correlated with chlorophyll content (30). An average value for each plant was calculated from six measurements on different leaves. Treatment effects on growth or foliar color were evaluated by one-way ANOVA and linear contrasts (39).

Experiment 1: strains in green ash seedlings. The first of three assays of strain aggressiveness was performed with seven phytoplasma strains and an untreated control, each replicated in six green ash seedlings. Potted seedlings that had completed two growth periods and vernalization were transferred to 19-liter pots and allowed to grow for 1 month before inoculation. During this time, they were trained to single stems as noted above, except that two small lateral branches were left low on each mainstem. These branches in each phytoplasma treatment were cleftgrafted with diseased leafy stem segments from an appropriate velvet ash donor plant that had been growing for 10 weeks. Control plants were not grafted. After a further 4 months, all plants were detopped and moved to cold storage. At the beginning of the fourth growth period, inoculated branches were removed. During this growth period, the trees were trained as noted above and were tested with DAPI. Foliar color measurements were made after 3 months, and height and diameter measurements were made after 4 months.

Experiment 2: strains in a green ash clone. Purposes of the experiment were to expand the array of strains assayed in experiment 1 , to perform the assay in genetically uniform plants, and determine the reproducibility of findings from experiment 1 . Cuttings from one green ash seedling were rooted, and this clone was increased in like manner until sufficient plants of adequate size (7- to 9-mm stem diameter $10 \mathrm{~cm}$ above the root collar) were available and had completed one cycle of growth and dormancy. This clone was known to contain a tobamovirus and a nepovirus. Viruses in these groups (usually Tomato mosaic virus or Tobacco ringspot virus) occur commonly in ash in New York State $(5,9,10)$. Virus particles were visualized by electron microscopy in expressed sap and were identified to genus level commercially (Agdia, Inc., Elkhart, IN) through use of polyclonal antibodies in an ELISA. Specific diagnoses were not made. The uniform viral contamination in all treatments was desired, because it was presumed to minimize the likelihood of falsely attributing to phytoplasmas a growth suppression or subnormal greenness actually caused by viruses.

Plants for this experiment were, at the beginning of their second growth period, allowed to grow for 1 month, then were distributed into groups of six, which were randomly assigned to 10 phytoplasma treatments and a control. Inoculations were performed by grafting each plant with two bark patches of diseased velvet ash that had been growing for 3 months. Control plants were grafted with their own bark. After a further 4 months, the plants were detopped and stored for dormancy. In the third growth period, plants were trained to single stems, tested with DAPI, and allowed to grow 4.5 months until final measurements were made.

Experiment 3: strains in periwinkle. Rooted periwinkle cuttings were grown for 7 months in small pots, with occasional pruning to control size and form, and then transplanted into 3-liter pots. One month later they were pruned to uniform size and inoculated by cleft-grafting one branch of each plant with a diseased scion. Controls received scions from a healthy plant. There were five replicate plants in each of 11 phytoplasma treatments and a control group. After 5 months, when foliar symptoms had developed in all phytoplasma treatments, all plants were pruned severely to leave a scaffold of uniform size with a few small shoots. The plants were then allowed to grow for 2 additional months, midway through which foliar greenness was measured. At 7 months after inoculation, the stems and leaves produced on each plant after the 5-month pruning

Table 1. Phytoplasma strains and their sources

\begin{tabular}{llll}
\hline Strain designation & \multicolumn{1}{c}{ Origin } & \multicolumn{1}{c}{ Host } & \multicolumn{1}{c}{ Collector } \\
\hline AshY1 & Ithaca, NY & Fraxinus americana & J. A. Matteoni \\
AshY2 & Enfield, NY & F. americana & W. A. Sinclair \\
AshY3 & Springdale, UT & F. velutina & W. A. Sinclair \\
AshY4 & Verbank, NY & F. americana & C. R. Hibben \\
AshY5 & St. Paul, MN & F. pennsylvanica & C. L. Ash \\
AshY6 & St. Paul, MN & F. pennsylvanica & C. L. Ash \\
AshY7 & Ann Arbor, MI & F. americana & W. A. Sinclair \\
AshY8 & Ann Arbor, MI & F. pennsylvanica & W. A. Sinclair \\
AshY12 & Inwood, WV & F. americana & W. A. Sinclair \\
LWB1 & Ithaca, NY & Syringa $\times$ prestoniae & W. A. Sinclair \\
LWB2 & Ottawa, Ont. & S. $\times$ josiflexa & C. R. Hibben \\
LWB3 & Boston, MA & S. patula & J. H. Alexander III \\
\hline
\end{tabular}

(termed dry weight increment below) were collected, dried, and weighed.

Experiments 4 and 5: strain competitiveness. Five periwinkle plants of uniform size that had grown 4 months from cuttings were each grafted with two scions containing strain AshY1 and two scions containing strain AshY3 (coinoculated). These strains were known to differ in aggressiveness. The grafted branches on each plant were approximately equidistant from one another. For controls, two periwinkle plants were each grafted with two AshY1 scions, and two plants each were grafted with two AshY3 scions. All plants were sampled for phytoplasma detection and identification 12, 20, and 28 weeks after inoculation. The sample from each plant consisted of randomly harvested young leaves (about 25 per plant) sufficient to obtain approximately $0.75 \mathrm{~g}$ of midveins for nucleic acid extraction (8). Phytoplasmal DNA was detected by polymerase chain reaction (PCR) using the phytoplasma-universal primer pair P1/P7 (26), which amplifies a 1.8-kb fragment of rDNA. Strains AshY1 and AshY3 were differentiated in plants that received both strains by RFLP analyses of the PCR products using restriction enzymes $A l u \mathrm{I}$ and HhaI (12).

Experiment 5 included treatments as in experiment 4 plus treatments in which periwinkle plants were sequentially inoculated with strains AshY1 and AshY3. Each of five plants was grafted initially with two scions infected with AshY1, and five additional plants received AshY3. Eleven weeks later, the plants were each grafted again with two scions containing the other strain. Plants coinoculated with AshY1 and AshY3 and the controls were sampled for detection of phytoplasmal DNA 11 and 23 weeks after grafting. Sequentially inoculated plants were sampled 11 weeks after receiving the second strain ( 22 weeks after the start of the experiment), and those plants still alive 23 weeks after the second inoculation were again sampled. Phytoplasmas were detected and strains identified as in experiment 4 . If only one strain was detected in a coinoculated or sequentially inoculated plant, the primary PCR product was diluted 1:40 and used as tem- 
plate for a nested PCR with primer pair P4/P7 (26). This primer pair mediates amplification of a 520-bp product at the $3^{\prime}$ end of the P1/P7 sequence. Amplified products of the nested PCRs were then analyzed with $A l u \mathrm{I}$ to distinguish the two AshY phytoplasma strains. Strain AshY1 possesses an $A l u \mathrm{I}$ restriction site within the $\mathrm{P} 1 / \mathrm{P} 4$ amplimer that is not possessed by strain AshY3 (12).

\section{RESULTS}

Assays of aggressiveness. Phytoplasma strains were highly significant sources of variation $(P \leq 0.001)$ in growth of ash trees or periwinkle in all three assays, and of variation in foliar greenness in the two experiments in which color was measured (Table 2). Six phytoplasma strains were common to all three experiments. Data for these strains are represented by hatched bars in the histograms (Figs. 1 and 2). Data for strains that were assessed in fewer than three experiments are represented by open bars. Where statistical significance of differences between means is mentioned below, the associated probability level is $\leq 0.01$ unless another level is stated.

The various strains caused growth suppression ranging from slight or imperceptible to severe in comparison to growth of phytoplasma-free plants (Fig. 1). Strains that caused the most severe growth suppression (AshY3 and AshY5) were consistent among experiments. In experiment 1, all strains except LWB2 suppressed growth significantly, and plants containing AshY3 grew significantly less than those containing any of three other strains. In experiment 2, all strains except AshY1 and
AshY4 suppressed ash growth significantly. Plants infected with AshY3 grew significantly less than those with AshY5 or AshY6, which in turn grew significantly less than those infected with any other strain. In periwinkle (experiment 3 ), the pattern of strain-associated variability in ash growth suppression was similar to that observed in ash, with the exceptions of strains AshY1 and LWB2. These two strains suppressed periwinkle growth significantly, although their influence on ash growth had been slight.

Foliar color varied significantly among phytoplasma strain treatments (Fig. 2). In ash seedlings (experiment 1), plants with strain AshY3 were severely chlorotic. Their measured greenness differed significantly from that of the controls and also from treatment LWB2. All other strain treatments were intermediate between, and nonsignificantly different from, AshY3 and LWB2. In periwinkles, all strains caused prominent chlorosis, and measured intensity of green color in every strain treatment differed from that of the controls. Chlorosis developed sooner and was more severe in plants with strains AshY3 and AshY5 than in other treatments. Measured color values were significantly lower $(P<0.05)$ for strains AshY3 and AshY5 than for AshY4 and LWB1. Plants in the other phytoplasma treatments had intermediate color not significantly different from either extreme. Correlations between measured foliar greenness and volume index (experiment 1 , ash seedlings) and between foliar greenness and dry weight increment (experiment 3 , periwinkle) were highly significant ( $r=0.75$ with $46 \mathrm{df}$ and 0.72 with $58 \mathrm{df}$, respectively).

Table 2. Analyses of variance in final volume index of ash trees, dry weight increment in periwinkle, and foliar greenness in ash and periwinkle as affected by strain of phytoplasma in the ash yellows group $^{\mathrm{a}}$

\begin{tabular}{|c|c|c|c|c|}
\hline $\begin{array}{l}\text { Experiment, variable, } \\
\text { and sources of variation }\end{array}$ & df & Mean square & $\boldsymbol{F}$ & $P$ \\
\hline \multicolumn{5}{|c|}{ Exp. 1: ash seedlings, volume index } \\
\hline Phytoplasma strains & 7 & 22,237 & 9.88 & $<0.001$ \\
\hline Error & 40 & 2,251 & & \\
\hline Total & 47 & & & \\
\hline \multicolumn{5}{|c|}{ Exp. 1: ash seedlings, foliar color } \\
\hline Phytoplasma strains & 7 & 280.7 & 4.60 & 0.001 \\
\hline Error & 40 & 61.0 & & \\
\hline Total & 47 & & & \\
\hline \multicolumn{5}{|c|}{ Exp. 2: ash clone, volume index } \\
\hline Phytoplasma strains & 10 & 78,617 & 10.47 & $<0.001$ \\
\hline Error & 51 & 7,506 & & \\
\hline Total & 61 & & & \\
\hline \multicolumn{5}{|c|}{ Exp. 3: periwinkle, dry weight increment } \\
\hline Phytoplasma strains & 11 & 303.1 & 16.29 & $<0.001$ \\
\hline Error & 48 & 18.6 & & \\
\hline Total & 59 & & & \\
\hline \multicolumn{5}{|c|}{ Exp. 3: periwinkle, foliar color } \\
\hline Phytoplasma strains & 11 & 335.4 & 6.43 & $<0.001$ \\
\hline Error & 48 & 52.1 & & \\
\hline Total & 59 & & & \\
\hline
\end{tabular}

${ }^{\text {a }}$ Volume index $=(\text { stem diameter in millimeters })^{2} \times$ height in centimeters $\times 10^{-3}$. Dry weight increment $=$ gain in biomass between 5 and 7 months after inoculation. Foliar greenness: measured with a Minolta SPAD-502 Chlorophyll Meter.
Correlation coefficients relating treatment means for ash volume index in experiments 1 and 2 and periwinkle dry weight increment in experiment 3 were calculated. These values were: 0.78 with $6 \mathrm{df}, P<0.05$, for ash volume index in experiments 1 and 2 ; 0.65 with $6 \mathrm{df}, P<$ 0.10 , for relationship of ash seedling volume index (experiment 1) to periwinkle dry weight increment; and 0.87 with $10 \mathrm{df}, P<0.01$, for relationship of ash ramet volume index (experiment 2) to periwinkle dry weight increment.

The six strains that were common to all three experiments were ranked least to greatest for growth impact in each experiment, and Spearman's rank correlation coefficient was calculated. This value was 0.89 with $4 \mathrm{df}, P=0.02$ for ranks in experiment 1 versus those in either of the other two experiments, and 1.0 for strain ranks in experiments 2 versus 3 .

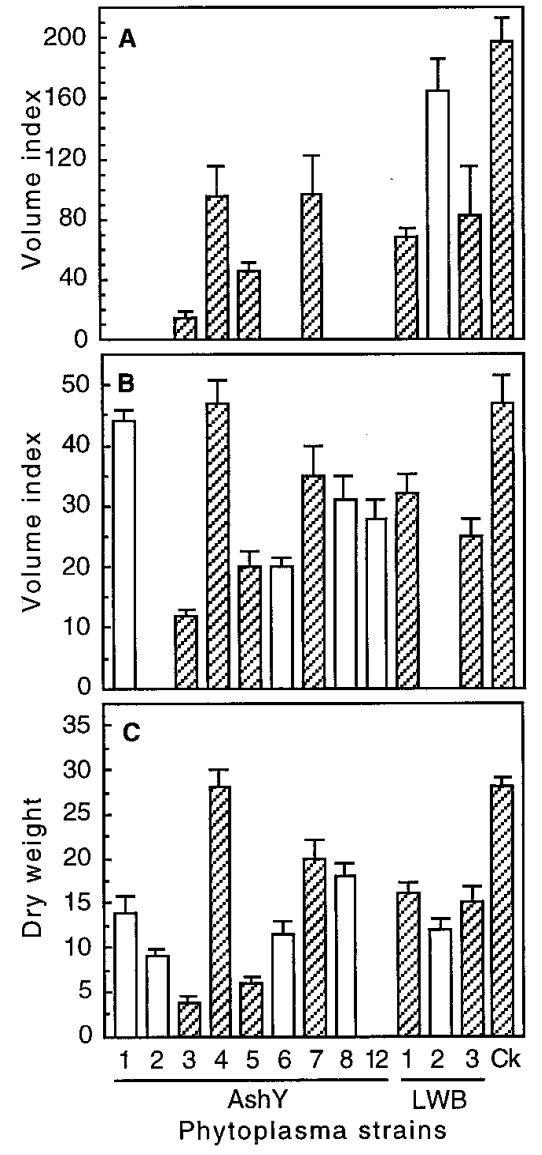

Fig. 1. Growth of green ash and periwinkle as affected by strains of ash yellows phytoplasmas. (A) Seven strains in green ash seedlings. (B) Ten strains in a green ash clone. (C) Eleven strains in periwinkle. Hatched bars identify treatments common to all three experiments. Green ash data are volume index [(stem diameter in millimeters $)^{2} \times$ height in centimeters $\times 10^{-3}$ ]. Periwinkle data are dry weight of biomass produced between 5 and 7 months after inoculation. $\mathrm{Ck}=$ noninoculated control. Standard errors are shown. 
Competition tests. Phytoplasma detection patterns in coinoculated plants were similar in two experiments and are illustrated for experiment 5 (Fig. 3A to D). In experiment 4, 3 months after inoculation, the RFLP profiles obtained with either AluI or HhaI from phytoplasmal rDNA amplified from each of four plants coinoculated with strains AshY1 and AshY3 were those of strain AshY3 (data not shown). The fifth coinoculated plant had been removed from the experiment, as the grafts on it failed. After a further 2 months, the AshY3 profiles were again detected in all four coinoculated plants. In addition, AshY1 profiles were detected in DNA from one of these plants. Seven months after grafting, only AshY3 profiles were detected in PCR products analyzed with either $A l u \mathrm{I}$ or $H h a \mathrm{I}$. RFLP profiles from PCRs with template DNA from plants singly inoculated with AshY1 or AshY3 (controls) at each time of sampling were characteristic of those strains (12).

In experiment 5, 11 weeks after coinoculation with AshY1 and AshY3, DNA amplified in primary PCRs from four of the five plants had the RFLP profiles of AshY3, while DNA from one plant had the profiles of AshY1 (Fig. 3A and B). Twelve weeks later, AshY3 was detected in all five plants, and AshY1 again in the one plant (Fig. 3C and D). In the five plants sequentially inoculated with AshY1 and then AshY3, only AshY1 profiles were detected
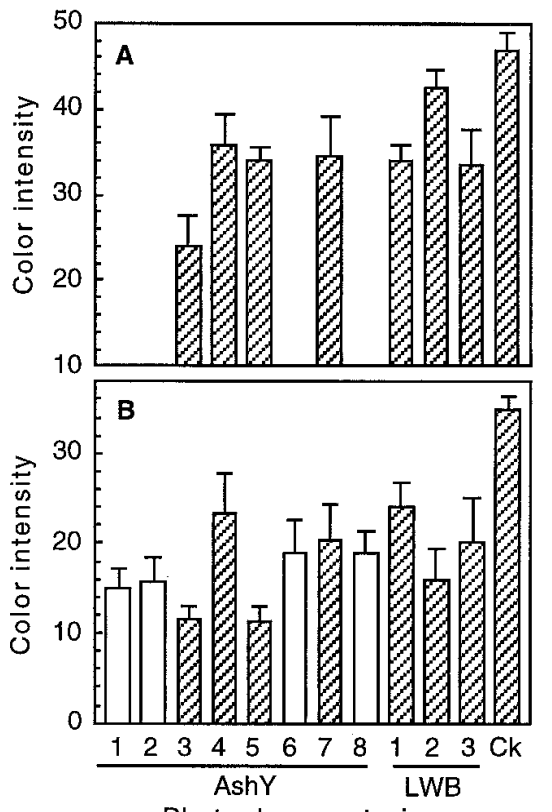

Phytoplasma strains

Fig. 2. Foliar color of green ash one growth period after inoculation, or of periwinkle 6 months after inoculation, as affected by strains of ash yellows phytoplasmas. (A) Seven strains in green ash seedlings. (B) Eleven strains in periwinkle. Hatched bars identify treatments common to both experiments. Units of color intensity are as recorded with a Minolta SPAD502 Chlorophyll Meter. $\mathrm{Ck}=$ noninoculated control. Standard errors are shown.
11 weeks after the second round of grafting. When plants were inoculated first with AshY3 and subsequently with AshY1, only AshY3 profiles were detected 11 weeks after the second round of grafting. At 23 weeks after the second inoculation, all five plants grafted first with AshY3 and subsequently with AshY1 were dead, as was one of the control plants singly infected with AshY3. All five plants that had been inoculated first with AshY1 and subse- quently with AshY3 were alive, as were both of the AshY1 controls. Analyses with AluI of the P4/P7 products of nested PCRs revealed only DNA of the single strains that had been detected in primary PCRs (data not shown).

\section{DISCUSSION}

Differences in aggressiveness sensu Van der Plank (40) of strains of a plant pathogen are indicated when strains vary in

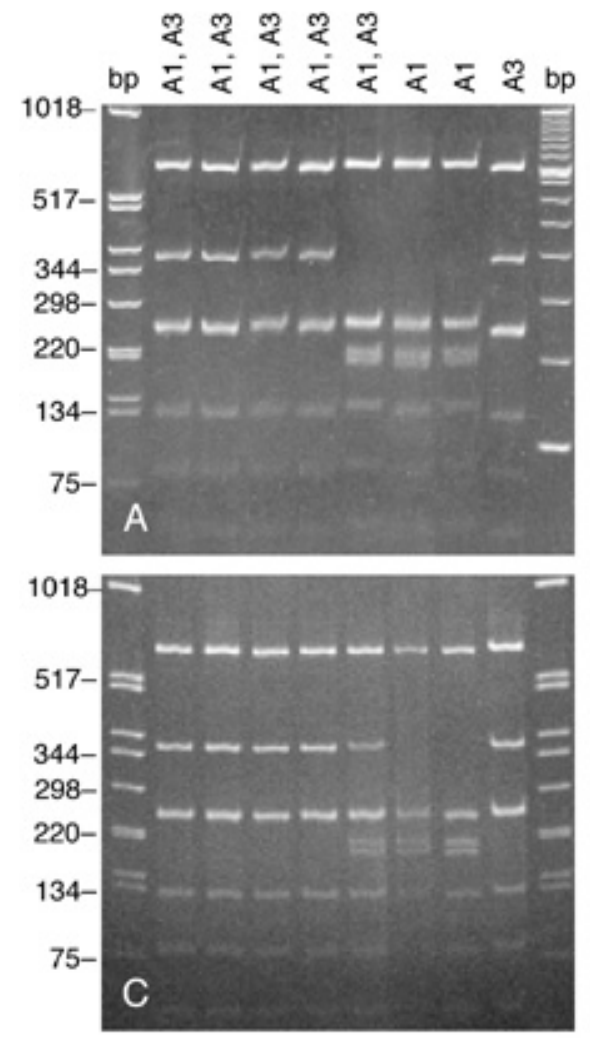

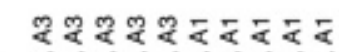

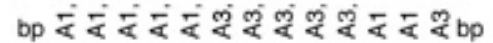

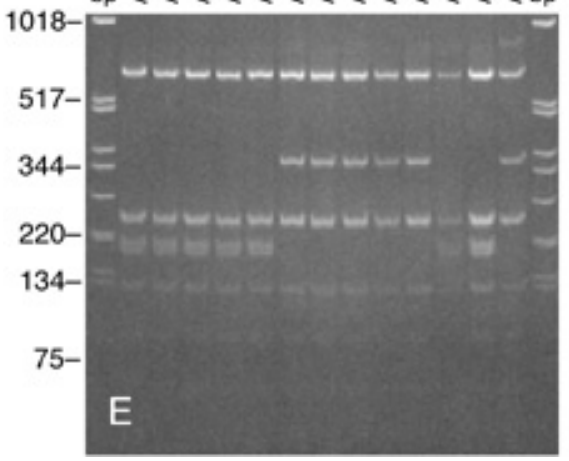

웅 \&
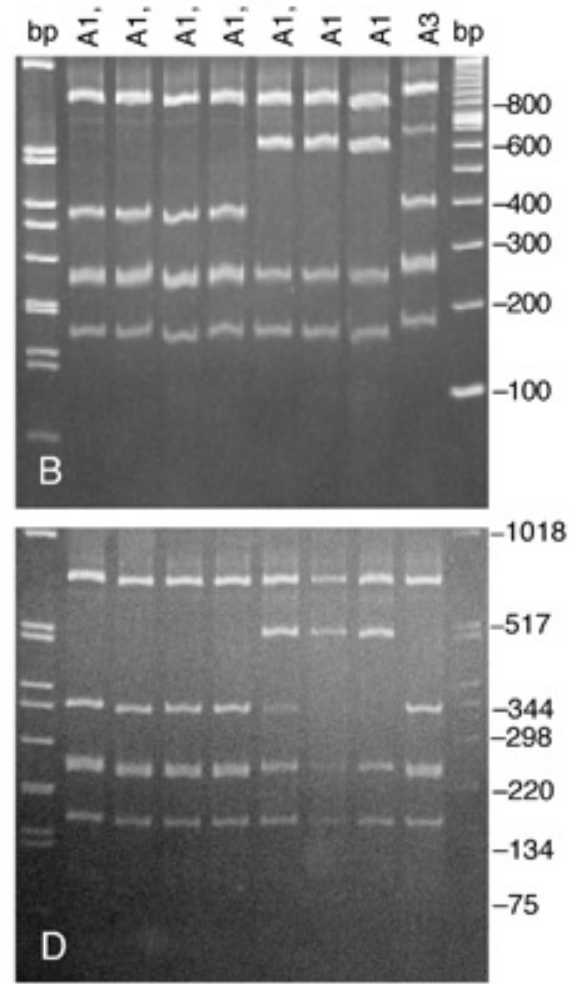

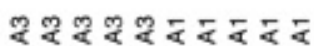

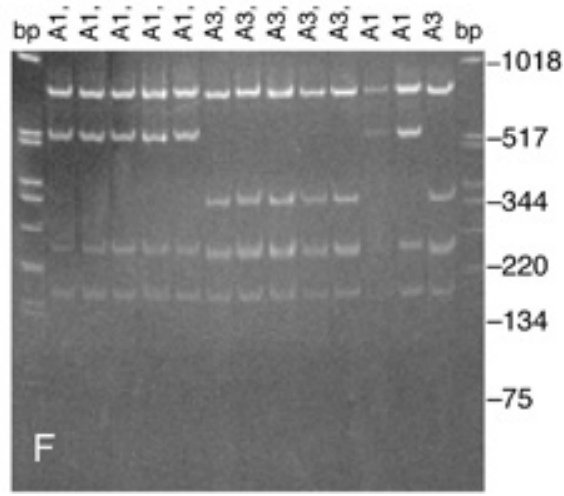

Fig. 3. Detection and identification of phytoplasma strains AshY1 and AshY3 through restriction fragment length polymorphism (RFLP) analysis of polymerase chain reaction (PCR)-amplified fragments of rDNA from periwinkle plants singly inoculated, coinoculated, or sequentially inoculated with these strains. A1 $=$ AshY1, A3 $=$ AshY3. (A, B) Analyses with restriction enzymes AluI and HhaI, respectively, 11 weeks after inoculation. Coinoculated plants are indicated by A1,A3, singly inoculated control plants by A1 or A3. Only AshY3 was detected in four of five coinoculated plants and only AshY1 in the fifth plant. (C, D) Analyses with $A l u \mathrm{I}$ and $H h a \mathrm{I}$, respectively, of samples from the same plants 23 weeks after inoculation, showing detection of AshY3 in all five coinoculated plants and detection of both AshY1 and AshY3 in one of these. (E, F) Analyses with AluI and HhaI, respectively, of DNA from sequentially inoculated plants and singly inoculated controls 23 weeks after the initial inoculation (12 weeks after the second inoculation). A1,A3 = strain AshY1 introduced before AshY3; A3,A1 = strain AshY3 introduced before AshY1. The strain introduced first was the only one detected in each of 10 plants. Molecular size standards are 1-kb ladder and, at right in panels A and B, 100-bp ladder (GIBCO BRL, Grand Island, NY). 
the amount of damage that they cause in plants but do not interact differentially with different hosts. By this criterion, six strains that were assayed in both green ash and periwinkle vary in aggressiveness. Strains AshY3 and AshY5 had the greatest impact on growth of both ash and periwinkle and were thus the most aggressive. Strains LWB1 and LWB3 were intermediate in aggressiveness, and AshY4 and AshY7 were least aggressive.

Strains AshY1 and LWB2, each tested only once in ash and once in periwinkle, were inconsistent in their growth impact, causing only slight, nonsignificant growth suppression in ash but greater and significant growth suppression in periwinkle in comparison to other strains and to controls. The differential response of ash and periwinkle to these strains cannot be explained on the basis of present data. Differential virulence (sensu Van der Plank [40]) of these strains to ash and periwinkle is possible and consistent with anecdotal observations. These strains have not caused noticeable growth suppression or broom formation in velvet ash, in which they are maintained, while strains AshY3 and AshY5 have caused these symptoms under the same conditions. In periwinkle, on the other hand, the reaction to strains AshY1 and LWB2 in experiment 3 were typical of the reactions observed during routine propagation of these strains over several years.

The first well-supported indication of variation in aggressiveness of phytoplasma strains that would now be considered members of one taxon was obtained by Kunze (16) during studies of apple proliferation. Phytoplasmas transmitted by grafting from three source trees that varied in disease severity caused correspondingly different degrees of symptom severity in five apple cultivars that varied in tolerance of infection. Kunze (16) concluded that "differences in the effect of the inoculum sources indicate the existence of strains with different virulence for the causal agent of apple proliferation." Two decades later, phytoplasma strains associated with apple proliferation were recognized as a taxonomically discrete group (24-26).

The present report is the first to document differences in aggressiveness among identified strains of a phytoplasmal taxon. Until recently, credible assays of strain variation could not be performed, because taxa had not been delineated. The AshY phytoplasma group is now regarded as a discrete taxon in a classification of phytoplasmas based primarily on differences in rDNA sequences and supported by phylogenetic analyses $(12,20,29)$. Another reason for delayed research on phytoplasmal aggressiveness is that very few taxa are represented by strain collections that can be readily inoculated to different plants (e.g., Apocynaceae and Oleaceae for periwinkle and ash, respectively).
Phytoplasma strains from both ash and lilac were assessed and compared in these tests, because ash and lilac naturally harbor phytoplasma strains that are not distinguishable by criteria used heretofore (12). Ash and lilac are closely related (graftcompatible) and often grow and become diseased in the same landscapes. Lilac strains were similar in aggressiveness to ash strains in the present work.

The variables used for growth assessments were chosen because they reflect phytoplasmal influence on biomass accumulation during defined periods after systemic colonization of host plants has occurred. For periwinkle, the variable "dry weight increment between months 5 and 7 after inoculation" was the most satisfactory of several biomass variables tested, because it maximized treatment-associated variance relative to error variance. For ash, volume index integrated height and diameter growth. This variable was used previously for assessing differences in tolerance of green ash families to AshY phytoplasmal infection (37). Volume indices in experiment 2 were smaller than in experiment 1 because the plants were younger by one growth period and probably also because they were infected with viruses. Ferris et al. (10) demonstrated suppression of green ash growth by nepoviruses and a phytoplasma, the latter agent having the greater effect.

Foliar color of diseased plants, measured in experiments 1 and 3, varied with phytoplasma strain and was correlated with growth variables. These findings were anticipated, because chlorosis and stunting are symptoms of phytoplasmal infection in periwinkle, while foliar greenness was previously related to growth rate in green ash affected by AshY (37). Foliar color in experiment 2 was not measured, because the virus-affected ash clone used for the experiment had abnormally light green leaves and foliar markings as noted previously in virus-infected ash (10).

In the strain-competition study, primary PCR/RFLP analysis seldom revealed the presence of both AshY strains in one plant, and then only in plants that were coinoculated. It appears, therefore, that systemic infection by one phytoplasma strain may interfere with either multiplication or systemic movement of a second strain, especially if the infections are asynchronous. More rapid population increase and/or movement of strain AshY3 than of AshY1 in periwinkle plants was indicated by AshY3 being the dominant strain in plants coinoculated with both strains. It is unlikely that inoculation of these plants with strain AshY1 failed, since each strain was transmitted through positive control grafts, and the method of inoculation was the one used for many years for routine propagation of phytoplasma strains. Since phytoplasma movement in plants is believed to be passive and to depend on the flow of photosynthetic assimilate in phloem sieve tubes (22), rapid multiplication is a more likely explanation than rapid movement for aggressiveness and dominance of strain AshY3. Aggressiveness of AshY3 could also be related to more or different metabolites released by this strain than by less aggressive strains.

Analysis of nested PCR products revealed DNA of only one strain in each of 13 assays. This result was not anticipated, because both AshY phytoplasma strains were presumed to have initiated colonization of each coinoculated plant. The detection of only one strain in these plants, as well as in sequentially inoculated plants, could reflect the presence of only one strain in each sample. Another possible explanation, however, is that only one strain was detected because amplification of phytoplasmal rDNA from scarce templates in template mixtures was inhibited by competitive interference from abundant templates, that is, from rDNA of the dominant phytoplasma strain in each plant.

Our assays also revealed continuing dominance of the first strain that colonized a plant, regardless of its aggressiveness. If strain AshY1 was already established in a plant, AshY3 was not able to displace it. This preemptive dominance of the first strain in a plant is apparently the same phenomenon described by Kunkel $(14,15)$ as cross-protection. The term cross-protection has multiple applications in contemporary plant pathology and immunology, referring to various phenomena at population and molecular levels (e.g., competition, interference with viral replication, induced systemic resistance, cross-reactivity of antigens and antibodies). Applied to phytoplasmal or viral interactions, crossprotection connotes protection by one strain or virus isolate against infection or damage by another closely related strain or isolate. The concept of preemptive dominance as here proposed is not linked to protection of the plant or as yet to any particular mechanism. This concept also accommodates possible interactions between phytoplasmas of different taxa, as discussed below.

Preemptive dominance could be due to physiologic and (or) physical changes in the plant. Inhibitory metabolites may accumulate during host colonization by the first strain (23), or as Kunkel (15) suggested, a population-limiting nutritional resource may be depleted by the first strain that colonizes a plant. Also, the first strain may cause sufficient dysfunction of phloem that further colonization by other strains is not possible. Interference with movement could be associated with suppressed export of assimilate from scions grafted on diseased shoots, which in turn may be associated with occlusion of sieve plate pores by phytoplasmas or callose or to collapse of sieve tubes, as occur in various phytoplasmal diseases $(2,3,6,27)$. 
Mechanisms of preemptive dominance of phytoplasma strains would be attractive topics for further research. Preemptive dominance can potentially be exploited for disease suppression, analogous to viral cross-protection, as has been done for apricot chlorotic leafroll (4).

Infection of plants by multiple phytoplasmas occurs in nature $(1,17)$. Natural infection of single plants by different strains of one phytoplasma group has been documented (1). However, dual or multiple infections have only been detected using nested PCRs $(1,17,20)$. Strains detected by primary PCR in plants supporting mixed infections have been presumed to be present in higher titer than those whose DNA was detected only in nested PCRs, and the former strains have been referred to as primary or predominant $(18,20$, and references cited therein). Preemptive dominance as well as aggressiveness and host suitability could determine primary versus secondary status of strains in mixed infections. Daire et al. (7) used several primary PCR techniques to detect various phytoplasma strains of the elm yellows and stolbur groups in grapevines, but they never detected two or more strains in one plant, even though different strains were detected in adjacent plants (E. Boudon-Padieu, personal communication). Preemptive dominance could account for such results.

The present demonstration of variation in AshY phytoplasma aggressiveness, together with knowledge that intraspecific variation in ash tolerance of phytoplasmal infection is under genetic control (37), furnishes a basis for interpreting the vitality or decline of naturally infected ash or lilac in terms of interacting host and pathogen genotypes influenced by local environment. Ash or lilac expressing phytoplasmal tolerance $(13,35,37)$ or infected with strains of low aggressiveness may grow more or less normally for many years, while intolerant plants, especially those infected by aggressive strains, may decline and die prematurely. Their impairment is exacerbated by environmental stresses, notably drought and competition with other plants. Relationships between competition and AshY-associated decline are documented for $F$. americana (white ash) and green ash (38).

Strain AshY3, the most aggressive in every test, has consistently induced foliar yellowing, sterility, and death in periwinkle more rapidly than do other strains in our collection. This strain is also lethal to small potted white ash or green ash after transmission by grafting (W. Sinclair, unpublished). This lethality may be related not only to its multiplication rate but also to the population level attained in its hosts or to virulence factors that it produces in greater quantity than other strains do. Our experiments were not designed to assess population levels. Phytoplasmal virulence factors are still unknown.
Strain AshY3 is also genetically distinct from strains found in eastern and midwestern United States (12). It came from a locality (southwestern Utah) and host $(F$. velutina) in which symptoms of AshY are usually subtle or imperceptible $(33,34)$. It appears from our studies that if this strain or one with similar aggressiveness were introduced into eastern North America, it could cause serious damage to less tolerant Fraxinus species and perhaps also to $S y-$ ringa growing in these regions.

\section{ACKNOWLEDGMENTS}

We thank J. H. Alexander III, C. L. Ash, C. R. Hibben, and J. A. Matteoni for phytoplasma strains, and E. Boudon-Padieu, N. A. Harrison, T. $\mathrm{H}$. Harrington, and an anonymous reviewer for helpful comments about the manuscript. This research was supported by the USDA McIntireStennis Cooperative Forestry Program.

\section{LITERATURE CITED}

1. Alma, A., Davis, R. E., Vibio, M., Danielli, A., Bosco, D., Arzone, A., and Bertaccini, A. 1996. Mixed infection of grapevines in northern Italy by phytoplasmas including $16 \mathrm{~S}$ rRNA RFLP subgroup 16SrI-B strains previously unreported in this host. Plant Dis. 80:418-421.

2. Braun, E. J., and Sinclair, W. A. 1976. Histopathology of phloem necrosis in Ulmus americana. Phytopathology 66:598-607.

3. Braun, E. J., and Sinclair, W. A. 1978. Translocation in phloem necrosis-diseased American elm seedlings. Phytopathology 68:17331737.

4. Castelain, C., Chastelliere, M. G., Jullian, J. P., Morvan, G., and Lemaire, J. M. 1997. Control of apricot chlorotic leaf roll. Phytoma 49:39-44.

5. Castello, J. D., Amico, L. A., and O'Shea, M. T. 1984. Detection of tobacco mosaic and tobacco ringspot viruses in white ash trees by enzyme-linked immunosorbent assay. Plant Dis. 68:787-790.

6. Credi, R. 1994. Occurrence of anomalous mycoplasma-like organisms in grapevine yellows-diseased phloem. J. Phytopathol. 142:310-316

7. Daire, X., Clair, D., Reinert, W., and BoudonPadieu, E. 1997. Detection and differentiation of grapevine yellows phytoplasmas belonging to the elm yellows group and to the stolbur subgroup by PCR amplification of non-ribosomal DNA. Eur. J. Plant Pathol. 103:507514.

8. Dellaporta, S. L., Wood, J., and Hicks, J. B. 1983. A plant DNA minipreparation: Version II. Plant Mol. Biol. Rep. 1:19-21.

9. Ferris, M. A., and Castello, J. D. 1988. Detection of tomato ringspot virus in white ash and adjacent vegetation in central New York. Can. J. For. Res. 18:813-817.

10. Ferris, M. A., Castello, J. D., and Sinclair, W. A. 1989. Effects of virus and mycoplasmalike organism infection on green and white ash. Phytopathology 79:579-583.

11. Griffiths, H. M., Hill, G. T., and Sinclair, W. A. 1998. Ash yellows phytoplasmas, a coherent, widely distributed group in North America. (Abstr.) Int. Congr. Plant Pathol., 7th. Edinburgh, Scotland.

12. Griffiths, H. M., Sinclair, W. A., Smart, C. M., and Davis, R. E. 1999. The phytoplasma associated with ash yellows and lilac witches'broom: 'Candidatus Phytoplasma fraxini.' Int. J. Syst. Bacteriol. 49:1605-1614.

13. Hibben, C. R., and Franzen, L. M. 1989. Susceptibility of lilacs to mycoplasmalike organisms. J. Environ. Hortic. 7:163-167.
14. Kunkel, L. O. 1936. Immunological studies on the three peach diseases, yellows, rosette, and little peach. Phytopathology 26:201-219.

15. Kunkel, L. O. 1955. Cross protection between strains of yellows-type viruses. Adv. Virus Res. 3:251-273.

16. Kunze, L. 1976. The effect of different strains of apple proliferation on the growth and crop of infected trees. Mitt. Biol. Bundesanst. Land-Forstwirtsch. Berlin-Dahlem 170:107115.

17. Lee, I.-M., Bertaccini, A., Vibio, M., Gundersen, D. E., Davis, R. E., Mittempergher, L. Conti, M., and Gennari, F. 1995. Detection and characterization of phytoplasmas associated with disease in Ulmus and Rubus in northern and central Italy. Phytopathol. Mediterr. 34:174-183.

18. Lee, I.-M., Gundersen, D. E., Hammond, R. W., and Davis, R. E. 1994. Use of mycoplasmalike organism (MLO) group-specific oligonucleotide primers for nested-PCR assays to detect mixed-MLO infections in a single host plant. Phytopathology 84:559-566.

19. Lee, I.-M., Gundersen-Rindal, D. E., and Bertaccini, A. 1998. Phytoplasma: Ecology and genomic diversity. Phytopathology 88:1359-1366

20. Lee, I.-M., Gundersen-Rindal, D. E., Davis, R. E., and Bartoszyk, I. M. 1998. Revised classification scheme of phytoplasmas based on RFLP analyses of $16 \mathrm{~S}$ rRNA and ribosomal protein gene sequences. Int. J. Syst. Bacteriol. 48:1153-1169.

21. Li, H., Qiu, B., Shi, C., Jin, K., Zhou, Q., and Huang, X. 1997. PCR amplification of $16 \mathrm{~S}$ rDNA of phytoplasma associated with cherry fasciated disease and RFLP analysis. For. Res. 10:478-481.

22. McCoy, R. E. 1979. Mycoplasmas and yellows diseases. Pages 229-264 in: The Mycoplasmas. Vol. III. Plant and Insect Mycoplasmas. R. F. Whitcomb and J. G. Tully, eds Academic Press, New York.

23. Musetti, R., Scaramagli, S., Vighi, C., Pressacco, L., Torrigiani, P., and Favali, M. A. 1999. The involvement of polyamines in phytoplasma-infected periwinkle (Catharanthus roseus L.) plants. Plant Biosyst. 133:37-45.

24. Schneider, B., Ahrens, U., Kirkpatrick, B. C., and Seemüller, E. 1993. Classification of plant-pathogenic mycoplasma-like organisms using restriction site analysis of PCR-amplified 16S rDNA. J. Gen. Microbiol. 139:519527.

25. Schneider, B., and Seemüller, E. 1994. Studies on taxonomic relationships of mycoplasma like organisms by Southern blot analysis. J . Phytopathol. 141:173-185.

26. Schneider, B., Seemüller, E., Smart, C. D., and Kirkpatrick, B. C. 1995. Phylogenetic classification of plant pathogenic mycoplasma-like organisms or phytoplasmas. Pages 369-380 in: Molecular and Diagnostic Procedures in Mycoplasmology, Vol. 1. S. Razin and J. G. Tully, eds. Academic Press, San Diego.

27. Schneider, H. 1945. Anatomy of buckskindiseased peach and cherry. Phytopathology 35:610-635.

28. Seemüller, E. 1976. Investigations to demonstrate mycoplasmalike organisms in diseased plants by fluorescence microscopy. Acta Hortic. 67:109-112.

29. Seemüller, E., Marcone, C., Lauer, U., Ragozzino, A., and Göschl, M. 1998. Current status of molecular classification of the phytoplasmas. J. Plant Pathol. 80:3-26.

30. Sibley, J. L., Eakes, D. J., Gilliam, C. H., Keever, G. J., Dozier, W. A., Jr., and Himelrick, D. G. 1996. Foliar SPAD-502 meter values, nitrogen levels, and extractable chloro- 
phyll for red maple selections. HortScience 31:468-470.

31. Sinclair, W. A., and Griffiths, H. M. 1994. Ash yellows and its relationship to dieback and decline of ash. Annu. Rev. Phytopathol. 32:49-60.

32. Sinclair, W. A., Griffiths, H. M., and Davis, R. E. 1996. Ash yellows and lilac witches'broom: Phytoplasmal diseases of concern in forestry and horticulture. Plant Dis. 80:468475 .

33. Sinclair, W. A., Griffiths, H. M., and Treshow, M. 1993. Impact of ash yellows mycoplasmalike organisms on radial growth of natu- rally infected white, green, and velvet ash. Can. J. For. Res. 23:2467-2472.

34. Sinclair, W. A., Griffiths, H. M., and Treshow, M. 1994. Ash yellows in velvet ash in Zion National Park, Utah: High incidence but low impact. Plant Dis. 78:486-490.

35. Sinclair, W. A., Griffiths, H. M., and Whitlow, T. H. 1997. Comparisons of tolerance of ash yellows phytoplasmas in Fraxinus species and rootstock-scion combinations. Plant Dis. 81:395-398.

36. Sinclair, W. A., Iuli, R. J., Dyer, A. T., and Larsen, A. O. 1989. Sampling and histological procedures for diagnosis of ash yellows. Plant Dis. 73:432-435.

37. Sinclair, W. A., Whitlow, T. H., and Griffiths, H. M. 1997. Heritable tolerance of phytoplasmal infection in green ash. Can. J. For Res. 27:1928-1935.

38. Smallidge, P. J., Leopold, D. J., and Castello, J. D. 1991. Structure and composition of forest stands affected and unaffected by ash yellows. Plant Dis. 75:13-18.

39. Snedecor, G. W., and Cochran, W. G. 1989. Statistical Methods, 8th ed. Iowa State University Press, Ames.

40. Van der Plank, J. E. 1968. Disease Resistance in Plants. Academic Press, New York. 